\title{
An Examination on Cloud Computing Future, Privacy of Data and Possibilities
}

\author{
Supriyono, Dodik Ariyanto, Nongmaithem Ajith Singh, K. Shankar, Phong Thanh Nguyen, Robbi \\ Rahim
}

\begin{abstract}
Cloud computing is the theoretical basis for future computing. All the global frameworks are now looking up to architecture which is purely based on cloud. Being the core of such a large web of network, it is important to consider the security aspects in a cloud based computing environment. This has resulted in a new research trend on the security issues of cloud. Cloud is a popular paradigm with extreme abilities and benefits for trending ICT environment. On the other end the major concern came in terms of security and privacy while adopting the cloud technology. This article is an effort to cover the challenges in fields like storage, virtualization and communication in cloud.Also it is a try to elaborate relevance of current cryptographic approach in order to increase security of cloud in ICT.
\end{abstract}

Keywords : Cryptography, Secure Data, visualization.

\section{INTRODUCTION}

Starting from the communication system of second world war to current era of highly secured computational protocols cryptography remains a crucial topic. Comparatively now a days cryptography is not confined only up-to the encryption rather it aims over data protection also,as a result present cryptography includes various mechanisms to achieve nonrepudiation,authentication and integrity of data. When computational ability of machines is continuously increasing the complexity of cryptography algorithm also need to increase in order to maintain importance in ICT based services.

In today's World, Cloud Computing is gaining highest popularity as one of the most creative technological approach that has revolutionized the way of computing. Cloud computing has Internet as its ground which provides the user a foundation of shared computer processing resources instead of buying all the hardware/software.

Inadequacy in ensuring proper security insurance while using cloud and lead to higher expenditure and degradation

Revised Manuscript Received on July 22, 2019.

* Correspondence Author

Supriyono, Universitas Muria Kudus, Indonesia. E-mail: supriyono.si@umk.ac.id

Dodik Ariyanto, Universitas Udayana, Indonesia

Nongmaithem Ajith Singh, Assistant Professor, Department of Computer Science, South East Manipur College, Manipur, India. E-mail: ajithex@gmail.com

K. Shankar, Department of Computer Applications, Alagappa University, Karaikudi, India. E-mail: shankarcrypto@gmail.com

Phong Thanh Nguyen*, Department of Project Management, Ho Chi Minh City Open University, Vietnam. E-mail: phong.nt@ou.edu.vn

Robbi Rahim, Sekolah Tinggi Ilmu Manajemen Sukma, Medan, Indonesia of business, thus harming the potential advantages of cloud computing. When switching to cloud computing, users and companies need to have an adequate insight of possible security asset and risks that come with cloud computing.

\section{CLOUD COMPUTING}

One of the internet-established computing is cloud computing that administers on-spot appeal for shared resources and data depending upon the requirement by computer and other devices. It is a model that empowers all inclusive, accessible as needs be induction to a typical gathering of configurable registering assets, which can be immediately satisfied and dispatched with least work.

Cloud computing gives clients and endeavors numerous alternatives through which they can store and process their data in an outsider server farm whose good ways from the client's range may shift from over a town to over a landmass. Cloud computing relies upon shared pooling of assets to achieve respectability and economy of scale.

Cloud computing framework and situations are less difficult that even organizations can get to the best-of-breed business applications by basically taking advantage of the cloud.Though cloud offers various benefits in present ICT, in spite of that a bunch of security issues also challenges its usefulness. The article is an effort to present an positive impact of cryptography on these challenges, well managed

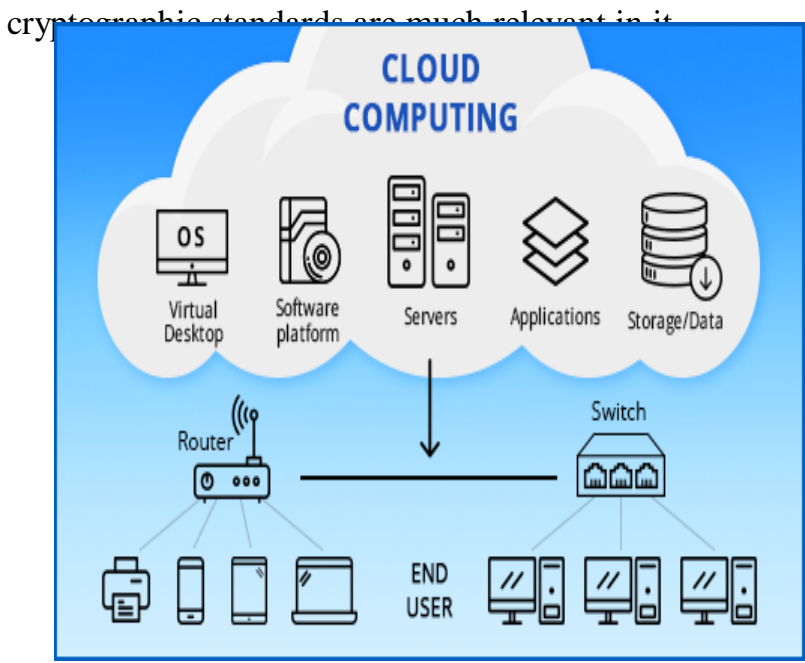

Figure 1:Cloud Computing

Cloud computing grants companies to bypass infrastructure investment in buying storage disks and servers. Also, it facilitates organization to target on their root business rather than 
wasting time and money on hardware requirements. Cloud computing enables enterprises to release their applications quickly and increase its running speed due to an enhanced manageability and lower upkeep cost and allows IT firms to maintain their resources according to their fluctuating demands.

Hence cloud computing is "pay according to use" model. cloud computing enables organizations to utilize a process asset, for instance a virtual machine (VMs), stockpiling or an application, as an as opposed to building and keeping up registering frameworks in their organization itself.

\section{COMPONENT OF CLOUD COMPUTING}

Cloud computing has three fundamental segments as pursues

I Client Computers: The end client can communicate with the cloud utilizing the customer PCs.

II Distributed Servers: The servers are circulated among the better places however acts like they as working with one another.

III Data Centers: Data focuses are the aggregation of servers

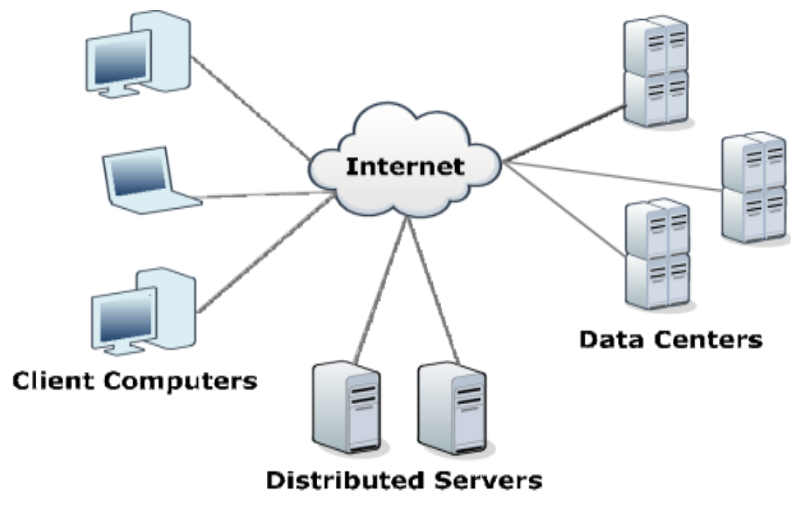

Figure 2 : Component of Cloud Computing

\section{SERVICES OF CLOUD COMPUTING}

I Software as a Service (SaaS):

The method for conveying application as an administration on the web is referred to as programming as an administration. Instead of introducing the product on his PC, the client can basically get to it through the web.

It makes the client free from dealing with the mind boggling programming and equipment. The SaaS clients don't have to purchase programming or equipment, keep up, and update. The main thing client must have a web association and after that entrance to the application is extremely simple. Model, Microsoft Office 365, Google Apps and so forth.

\section{Platform as a Service (PaaS):}

An improvement circumstance or stage is given to the purchasers as an organization in PaaS, whereupon customer can pass on their own one of a kind item and coding. The customer has the opportunity to construct his own applications that can continue running on the provider's establishment. Thing as a pro communities offers a predefined game plan of working structure and application server to get the organization furthest reaches of the applications. For example, LAMP (Linux, Apache, MySQL, and PHP), J2EE, Ruby, etc.

\section{Infrastructure as a Service (IaaS):}

Many registering assets are given by the IaaS as capacity, arrange, working framework, equipment, and capacity gadgets on interest. IaaS clients can get to the administrations utilizing a wide territory arrange, for example, the web. For instance, a client can make virtual machines by login to the IaaS stage.
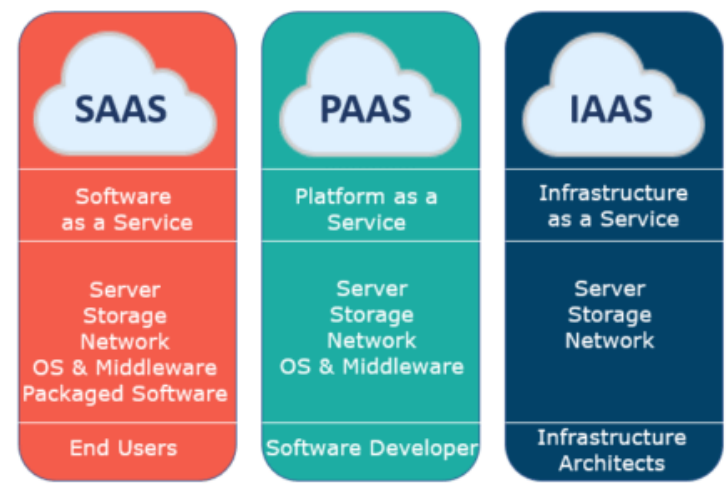

Figure 3: Cloud Computing Services

\section{DEPLOYMENT MODEL}

Public Cloud (or External Cloud) :

In this model, computing resources are capably provisioned over the Internet by methods for Web applications or Web organizations froutsidersom trusted in untouchable provider. Open fogs are constrained by untouchables, and applications from different customers are likely going to be consolidated on the cloud's servers, accumulating structures, and frameworks. Disregarding the way that the open cloud has persuading focuses regarding enthusiasm, there existing the covered peril of security, authoritative plan consistence and nature of organization $(\mathrm{QoS})$ requirements.

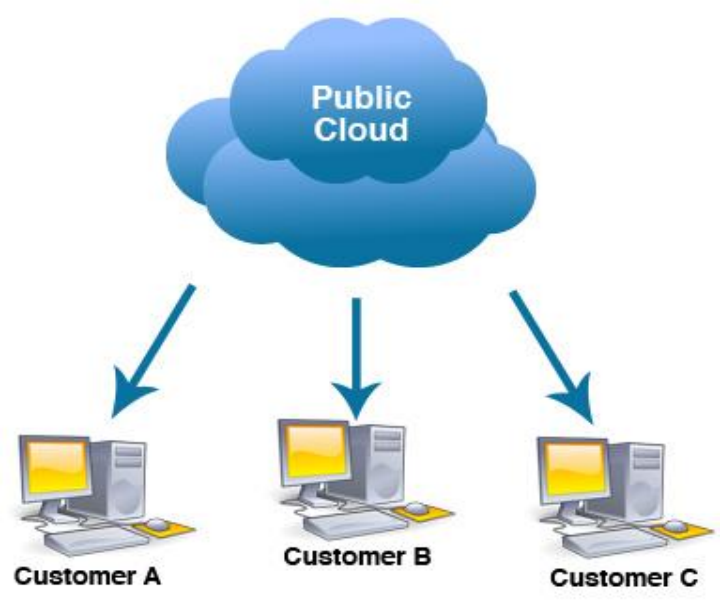

Figure 4: Public Cloud 


\section{- Private Cloud (or Internal Cloud) :}

In the private cloud arrangement, computing assets are utilized and constrained by a private venture. It is for the most part sent in the endeavors server farm and overseen by interior faculty or specialist co-op. The primary bit of leeway of this model is that the security, consistence, and QoS are under the influence of the ventures.

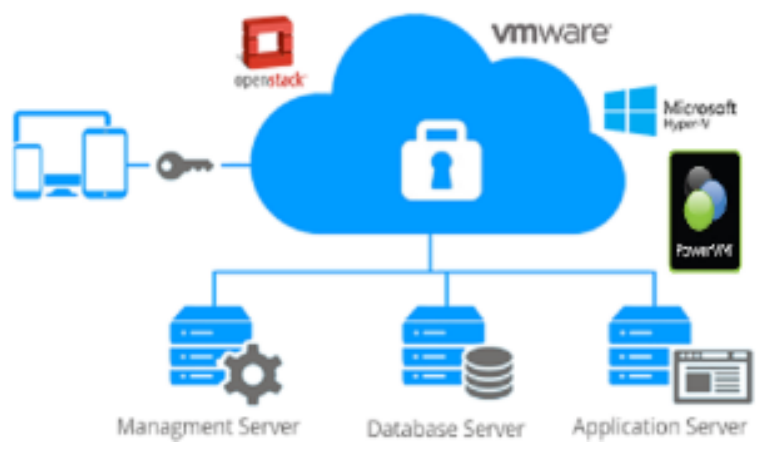

Figure 5: Private Cloud

\section{- Hybrid Cloud (or Mixed Cloud) :}

The Hybrid Cloud condition meets and joins distinctive open and private cloud models. It engages the undertaking applications to running state-determined exceptional weight in the private cloud, and referencing the open cloud for concentrated processing resources when zenith remaining job needing to be done occurs. Cross breed fogs present the multifaceted idea of choosing how to course applications across over both an open and private cloud.

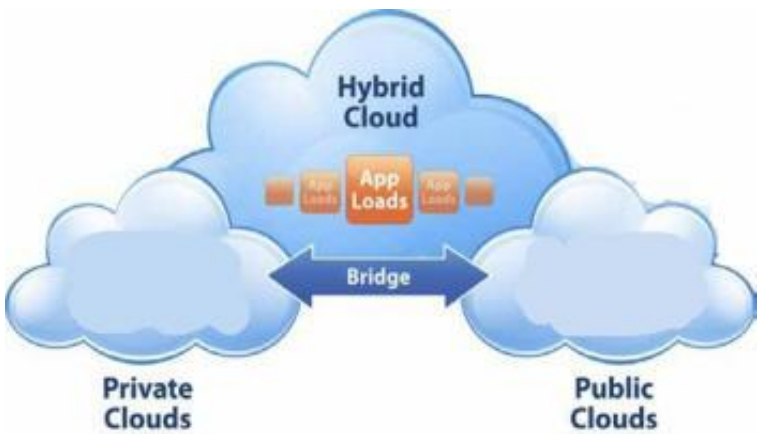

Figure 6:Hybrid Cloud

\section{- Community Cloud(or Group Cloud):}

In this Community sending model a couple of affiliations together create and offer cloud structure similarly as procedures, requirements, characteristics, and concerns. The cloud system structures into a degree of monetary versatility and impartial parity. The cloud establishment could be encouraged by a third-social affair dealer or inside one of the relationship in the system. This is rising cloud used by various individual to individual correspondence site like facebook, orkut, etc.

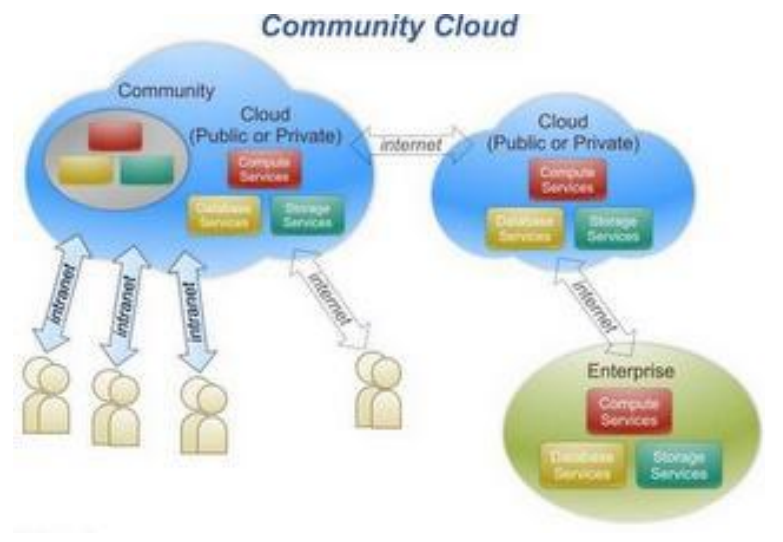

Figure 7: Community Cloud

\section{SECURITY RISK ASSOCIATED TO CLOUD COMPUTING}

The greater part of the agents are not very much aware about the security issues and the dangers worried about cloud computing. It is by all accounts an enormous hindrance to the selection of cloud administrations. The data in regards to how to oversee information security inside a cloud, information protection in the cloud, cloud security benchmarks, the administrative and consistence ramifications of relocating to a cloud model, and so forth ought to be surely known before receiving the cloud administration and arrangements.

\section{A. Loss of governance}

Customers concede control to the supplier over many issues that may endanger security. Yet cloud service agreements might not assure a guarantee to clear up such problems from cloud provider's side, thus leading to gap in security measures.

\section{B. Responsibility Ambiguity}

Authority over provision of security may be divided between the supplier and the user, with the possibility for crucial parts of the defenses to be left unprotected if there is confusion in proper allocation security responsibility.

\section{Authentication and Authorization}

This is the most critical concern. The basic concept of cloud computing says that essential data can be accessed from anywhere through internet thus making it primary necessity to associate certain identity to users in order to distinguish them as user for any company may be its employees, contractors, customers etc.

\section{Isolation Failure}

The key characteristic of public cloud is sharing of resources as well as multi-tenancy. The major risk occurs due to failure of the tool that separates the usage space for storage, routing, memory etc amongst holder.

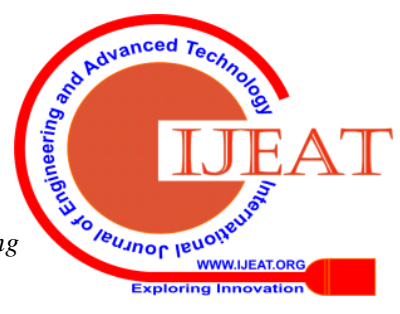




\section{An Examination on Cloud Computing Future, Privacy of Data and Possibilities}

\section{E. Compilance and Legal Risks}

The cloud service customer's money in acquiring recognition may be forfeited if the cloud service provider is not able to give proof of their own conformity with the compatible need or does not allow the customer to review. The cloud customer must verify the authentic certification of the cloud provider.

\section{F. Handling of Security Incidents}

The detection, recording and appropriate measures should be taken by the cloud service provider against the security breaches that might happen, as these incidents my harm the privacy of the customer. Proper negotiation should be proposed by the customer so that they get notified about such breaches on time.

\section{G. Management Interface Vulnerability}

The public cloud provider allow admittance to more resource than the conventional hosting provider, moreover, their interfaces can be accessible through internet, thus there is an increased risk, especially when there is remote access and browser susceptibility.

\section{H. Application Protection}

Since the duty of foundation security is designated to the cloud supplier, the organizations must reset the security at the system level, apply more control at all three level, to be specific, client, application and information level. The remaining burden that is conveyed to cloud administrations must have the client access control just as assurance in the server center.

\section{Data Protection}

The disclosure of vital data as well as its loss or unavailability is the major concern. The cloud customer might find it difficult to efficiently review the information handling methods of the provider. This issue is often annoying if there are multiple transfers of data.

\section{J. Service Unavalability}

Hardware, software or communication network breakdown may lead to unavailability of service to the customer.

\section{CLOUD SECURITY}

As customers changeover their applications and data to the cloud, it is important for them to maintain security.

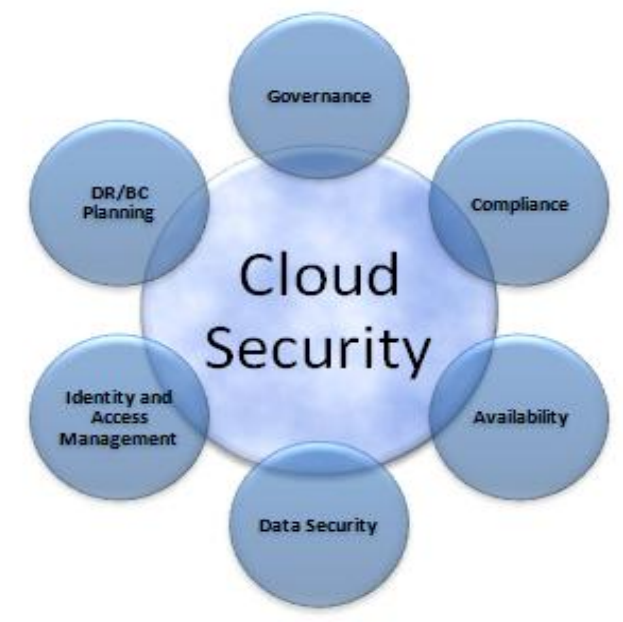

Figure 8: Cloud Security
This section gives an authoritative series of methods for customers to calculate and administer the security for usage of cloud services, with the aim of reducing risk and delivering proper support

A. : Ensure effective governance, risk and compliance processes exist

Almost all companies have incorporated security and consent plans and methods that are used to save their property and corporate belongings. These plans and methods framed are founded upon study of the effects that might happen if these assets get compromised. A set-up of principles and steps are set up to limit hazard and fill in as a measure for the administration and check of consistence. These sets of principles that the undertaking security plan and quality improve strategies make the endeavor security administration, hazard the board, and consistence model.

B. Manage people, roles and identities

In cloud there are provider's employees who have access to the customer's data as well as customer's employee who perform operation on system given by provider. Hence customer must be aware of the methods the provider has implied in order to govern the accessibility given to the customer's data. Also, provider should ask the customer to allot roles of authorization to their user in order to maintain their security approach.

C. Enforce privacy policies

Most important concern is privacy and data protection. There are rules and laws that help in regulating the storage, usage and ownership of the personally identifiable information (PII).though privacy and security are closely related, yet there is a hairline difference between them. Security is oriented around protecting against attacks whereas privacy is related to keeping crucial personal data of the organization safe from any theft possibilities.

D. Ensure cloud networks and connections are secure

A service provider must be able to distinguish between safe and malicious network traffic, allowing only the genuine network traffic and stopping the malevolent ones. But the cloud provider might not know the connection that the customer plans to send or receive. Hence the customer must give a briefing to the provider regarding the network traffic that the customer considers as legitimate.

E. Evaluate security controls on physical infrastructure and facilities

Physical and infrastructure facility security is very crucial in an IT security system. In cloud computing, provision of this security is the responsibility of the service provider. Hence provider must assure and insure the customer regarding the appropriate security policies that it follows and the parameters it has set for proper functioning of the security.

\section{CONCLUSION}

Despite the fact that security and protection benefits in the cloud can be tweaked and overseen by experienced gatherings that can possibly give proficient security the executives and risk appraisal benefits, the issues we've talked about here demonstrate that current security and security arrangements must be basically reexamined concerning their fittingness for mists. 
Though cloud offers various benefits in present ICT, in spite of that a bunch of security issues also challenges its usefulness. The article is an effort to present an positive impact of cryptography on these challenges, well managed cryptographic standards are much relevant in it.

\section{REFERENCES}

1. Garrison, G., Kim, S., Wakefield, R.L.: Success Factors for Deploying Cloud Computing. Commun.ACM.55, 62-68 (2012).

2. Herhalt, J., Cochrane, K.: Exploring the Cloud: A Global Study of Governments` Adoption of Cloud (2012).

3. Sales force, -CRMIl, http://www.salesforce.com/.

4. BisongandSMRahman,"An overview ofthe security concerninenterprise cloudcomputing,"CoRR,vol.abs/1101.5613,2011.

5. TMather,SKumaraswamy ,andSLatif,Cloud Securityand Privacy:Anenterpriseperspective onriskandconpliance.O'ReillyMedia,Inc.,2009.

6. Tang, Yang, Patrick PC Lee, John CS Lui, and Radia Perlman. "Fade: Secure overlay cloud storage with file assured deletion." In Security and Privacy in Communication Networks, pp 380-397.Springer Berlin Heidelberg, 2010

7. Chienwattanasook, K., Wattanapongphasuk, W., Prianto, A., \& Jermsittiparsert, K. 2019. "Corporate Entrepreneurship and Business Performance of Logistic Companies in Indonesia." Industrial Engineering \& Management Systems 18 (3): 538-547.

8. Dawabsheh, M., Hussein, A., \& Jermsittiparsert, K. 2019. "The Triangular Relationship between TQM, Organizational Excellence and Organizational Performance: A Case of Arab American University Palestine." Management Science Letters 9 (6): 921-932.

9. Jermsittiparsert, K., Siam, M., Issa, M., Ahmed, U., \& Pahi, M. 2019. "Do Consumers Expect Companies to Be Socially Responsible? The Impact of Corporate Social Responsibility on Buying Behavior." Uncertain Supply Chain Management 7 (4): 741-752.

10. Syazali, M., Putra, F., Rinaldi, A., Utami, L., Widayanti, Umam, R., \& Jermsittiparsert, K. 2019. "Partial Correlation Analysis Using Multiple Linear Regression: Impact on Business Environment of Digital Marketing Interest in the Era of Industrial Revolution 4.0." Management Science Letters 9 (11): 1875-1886.

11. Sae-Lim, P. \& Jermsittiparsert, K. 2019. "Is the Fourth Industrial Revolution a Panacea? Risks toward the Fourth Industrial Revolution: Evidence in the Thai Economy." International Journal of Innovation, Creativity and Change 5 (2): 732-752.

12. Chatchawanchanchanakij, P., Arpornpisal, C., \& Jermsittiparsert, K. 2019. "The Role of Corporate Governance in Creating a Capable Supply Chain: A Case of Indonesian Tin Industry." International Journal of Supply Chain Management 8 (3): 854-864.

13. Hartinah, S., Suharso, P., Umam, R., Syazali, M., Lestari, B., Roslina, R., \& Jermsittiparsert, K. 2020. "Teacher's Performance Management: The Role of Principal's Leadership, Work Environment and Motivation in Tegal City, Indonesia." Management Science Letters 10 (1): 235-246.

14. Haseeb, M., Hussain, H., Slusarczyk, B., \& Jermsittiparsert, K. 2019. "Industry 4.0: A Solution towards Technology Challenges of Sustainable Business Performance.” Social Sciences 8 (5): 184.

15. Haseeb, M., Hussain, H., Kot, S., Androniceanu, A., \& Jermsittiparsert, K. 2019. "Role of Social and Technological Challenges in Achieving a Sustainable Competitive Advantage and Sustainable Business Performance." Sustainability 11 (14): 3811.

16. Haseeb, M., Kot, S., Hussain, H., \& Jermsittiparsert, K. 2019. "Impact of Economic Growth, Environmental Pollution, and Energy Consumption on Health Expenditure and R and D Expenditure of ASEAN Countries." Energies 12 (19): 3598.

17. Huda, S., Tsani, I., Syazali, M., Umam, R., \& Jermsittiparsert, K. 2020. "The Management of Educational System Using Three Law Auguste Comte: A Case of Islamic Schools.” Management Science Letters 10 (3) (In press), DOI: 10.5267/j.msl.2019.9.018.

18. Usak, M., Kubiatko, M., Shabbir, M., Dudnik, O., Jermsittiparsert, K., \& Rajabion, L. 2019. "Health Care Service Delivery Based on the Internet of Things: A Systematic and Comprehensive Study." International Journal of Communication Systems 32 (14): e4179.

19. Jermsittiparsert, K., Ambarita, D., Mihardjo, L., \& Ghani, E. 2019. "Risk-Return through Financial Ratios as Determinants of Stock Price: A Study from ASEAN Region." Journal of Security and Sustainability Issues 9 (1): 199-210.

20. Maseleno, A., Hardaker, G., Sabani, N., \& Suhaili, N. (2016). Data on multicultural education and diagnostic information profiling: Culture, learning styles and creativity. Data in brief, 9, 1048.
21. Maseleno, A., Huda, M., Jasmi, K. A., Basiron, B., Mustari, I., Don, A. G., \& bin Ahmad, R. (2019). Hau-Kashyap approach for student's level of expertise. Egyptian Informatics Journal, 20(1), 27-32.

Maseleno, A., Huda, M., Siregar, M., Ahmad, R., Hehsan, A., Haron, Z., ... \& Jasmi, K. A. (2017). Combining the previous measure of evidence to educational entrance examination. Journal of Artificial Intelligence, 10(3), 85-90.

23. Thabhiranrak, T. \& Jermsittiparsert, K. 2019. "Towards Sustainable Functioning of Organization: Women Empowernment and Corporate Management Culture.” Journal of Security and Sustainability Issues 9 (1): 321-332.

24. Chienwattanasook, K. \& Jermsittiparsert, K. 2019. "Impact of Entrepreneur Education on Entrepreneurial Self-Employment: A Case Study from Thailand." Polish Journal of Management Studies 19 (1): 106-116.

25. Jermsittiparsert, K., Sutduean, J., Sriyakul, T., \& Khumboon, R. 2019. "The Role of Customer Responsiveness in Improving the External Performance of an Agile Supply Chain.” Polish Journal of Management Studies 19 (2): 206-217.

26. Jermsittiparsert, K., Sutduean, J., \& Sriyakul, T. 2019. "Effect of Service Innovation and Market Intelligence on Supply Chain Performance in Indonesian Fishing Industry.” Industrial Engineering \& Management Systems 18 (3): 408-417.

27. Jermsittiparsert, K., Namdej, P., \& Somjai, S. 2019. "Green Supply Chain Practices and Sustainable Performance: Moderating Role of Total Quality Management Practices in Electronic Industry of Thailand." International Journal of Supply Chain Management 8 (3): 33-46.

28. Somjai, S. \& Jermsittiparsert, K. 2019. "The Trade-off between Cost and Environmental Performance in the Presence of Sustainable Supply Chain." International Journal of Supply Chain Management 8 (4): 237-247.

29. Jermsittiparsert, K. \& Sawasdee, A. 2012. "Formal Education for Non-Thai or Undocumented Person in Thailand amidst the Challenge of Nationalism and Transnationalism: A Case Study of Wat Sirimongkhol School, Samut Sakhon Province." Kasetsart Journal - Social Sciences 33 (2): 203-213.

30. Venters, W., Whitley, E.A.: A Critical Review of Cloud Computing: Researching Desires and Realities. J. Inf. Technol. 27, 179-197 (2012).

31. Musa, F. A. and Sani, S. M. (2016) 'Security Threats and Countermeasures In Cloud Computing', International Research Journal of Electronics \& Computer Engineering, 24.

32. Popović, K. and Hocenski, Ž. (2016) 'Cloud computing security issues and challenges', Research Gate.

33. Yang, H., Tate, M.: A Descriptive Literature Review and Classification of Cloud Computing Research. Commun.Assoc. Inf. Syst. 31 (2012).

34. Marston, S., Li, Z., Bandyopadhyay, S., Zhang, J., Ghalsasi, A.: Cloud computing - The Business Perspective. Decis. Support Syst. 51, 176-189 (2011) 